\title{
Transient Ischemic Attacks, CTCAE
}

National Cancer Institute

\section{Source}

National Cancer Institute. Transient Ischemic Attacks, CTCAE. NCI Thesaurus. Code C143886.

A disorder characterized by a brief attack (less than 24 hours) of cerebral dysfunction of vascular origin, with no persistent neurological deficit. 